\title{
NOTES
}

\section{"CROSSING BROOKLYN FERRY": THE SHAPING IMAGINATION}

In Specimen Days, Whitman recalled that his life in the 1840 s and 1850 s was "... curiously identified with Fulton Ferry." He remembered that from the ferryboat he saw ". . f full sweep, absorbing shows, accompaniments, surroundings." Then, in language reminiscent of the imagery in "Crossing Brooklyn Ferry," he went on:

What oceanic currents, eddies, underneath - the great tides of humanity also, with evershifting movements. Indeed, I have always had a passion for ferries; to me they afford inimitable, streaming, never-failing, living poems. The river and bay scenery, all about New York island, any time of a fine day - the hurrying, splashing sea-tides - the changing panorama of steamers, all sizes, . . . the myriads of white-sail'd schooners, sloops, skiffs. . . 1

To readers today, Whitman's word "panorama" denotes little more than simply a busy scene spread out in a wide perspective. In Whitman's time, "panorama" had a more specific context. Sometimes it was a building designed to house a work of art. John Vanderlyn's large panorama Versailles, for instance, extended over some 3000 square feet and the canvas demanded a rotunda big enough to contain it. John Banvard's Panorama of the Mississippi took up a different space. It was a canvas twelve feet high and three miles long. The painting was stored on large cylinders and unspooled before audiences. It took two hours to veiw the whole painting and hear Banvard's accompanying lecture. ${ }^{2}$

Whitman's fascination for panoramas, dioramas, and dime museums is well documented. Certainly he was a frequent visitor to Dr. Henry Abbott's museum of Egyptology. We do not know if he was among the crowds who lined up to experience Banvard's Panorama of the Mississippi in the late 1840s or if he ever visited the other popular panoramas of the day-Vanderlyn's, Frederick Catherwood's ferusalem, Henry Lewis's Mississipippi River scenes. But he was living at a time when large numbers of people did go to see them and to experience the "mute spectacles" of tableaux vivants, cycloramas, dioramas, serious museums, as well as cheap hoax collections.

Certainly he was aware enough to borrow the notion of a catalogued collection of pictures as the strategy for a poem. The uncollected poem "Pictures," written before 1855 , uses this metaphor of a gallery:

In a little house pictures I keep, many pictures hanging suspended-It is not a fixed house,

It is round-it is but a few inches from one side of it to the other.

But behold-it has room enough-in it, hundreds and thousands . . . 3

This fanciful conceit of the inside of his own head as a gallery crammed with suspended images is a scaled-down miniature of the building artists like Vanderlyn designed for their spectacular panoramas. And it is also a playful expression of the retentive power of the poet's own sensory memory. "Pictures" is a less skillful attempt to capture the visible world than either the later "Song of Myself" or "Crossing 
Brooklyn Ferry." Yet it presages something of the same strategy: a catalogue effect of montaged vivid scenes recalled from lived experience.

Museums offer a reassuring sense of encompassed, possessed objects. No matter how extensive the collection, how thick the catalogue, how immense the panoramic display, there are walls as termini. The catalogue can be printed, bound, and shelved. A museum is like the map or inventory of a conquered territory. But what of the paradoxically close at hand yet elusive experience of the ferryboat trip? Did it offer the same reassuring sense of possession? What strategies did Whitman employ to deal with the ferryboat experience?

For Whitman, the poet's imagination was an absorbing force, interpenetrating all experience. In "Crossing Brooklyn Ferry" the shaping imagination led the poet to a new self-awareness and a new awareness of the true nature of the perceptible world. And the poem itself is a paradigm of the active creative intelligence as well as a model of the external reality which is that intelligence's subject. "Crossing Brooklyn Ferry" is the record of the imagination working in heightened awareness, attempting to control the visible, multitudinous, fabulous, mundane world.

Emerson's doctrine of the "excited mind" at work is especially evident in Section 3 and Section 9. The motion of the sea gulls as they float and oscillate, the contrasting light and dark images, and above all, the poet's halo of divinity, the aureaole struck by the sunlight on the water, move towards an apprehension of singular objects merging into one collective identity. In the open air, in the huge simple space of outside, Whitman's act of continuing perception led him to the realization that reality-the epidermis of reality, the outward forms of things, those "dumb, beautiful ministers"-existed independently of him. Yet they actively supported his existence. Through his act of perception, he conferred a new reality on things. In the centre of a circular perspective, the landscape, as in "Pictures," was round. His vision flowed out to its reality and its reality flowed in to him. Thus, the action is both centrifugal and centripetal-things in the landscape's panorama "furnishing their parts" to his soul. And this reciprocating action resulted in the creation of the poem itself.

"Crossing Brooklyn Ferry" is thus both a result, an end product of a creative intelligence, and an action-generating agent. The poet, through the medium of the poem, confers a reality on the objects within the range of his perception which was not there before he saw it in his unique, personal way. One final irony: this moment of insight takes place in the last hours of a day in the last month of the year. The large irony, of course, is that the spiritual vision occurs during a mundane commuuter trip. If the plan for the whole of Leaves of Grass might be paralleled to Thomas Cole's four allegorical paintings, portraying Youth, Manhood, Old Age, etc., the single poem, "Crossing Brooklyn Ferry," finds its parallel in the larger panoramas and crowded museums. "Crossing Brooklyn Ferry" first appeared under the title "Sun-Down Poem" in the 1856 edition of Leaves. The title was changed in the 1881 edition. That original title seems static, like the title for a still life painting. The changed title more closely captures the motile essence of the poem's language. Everything in "Crossing Brooklyn Ferry" is in constant ceaseless motion. It is a motion which started before the poem begins and the ultimate message the poet leaves us is that the motion will continue for generations to come into infinite time. The word "generations" itself, like "crossing," "flowing," etc. suggests burgeoning fecund life and incessant action.

Whitman's encompassing imagination initially perceived the panorama of the 
scene from the ferryboat as a collection of knowable objects. He took the objects in, knew them, named and finally loved them. Yet this list of named things, the inventory thus created, becomes one more object to add to the already existing world. Also, one object is left out of the process. That object is the perceiving self. So Whitman adds that self to the inventory in lines 33-34 of Section 3:

Look'd at the fine centrifugal spokes of light round the shape of my head in the sunlit water...

Thus the poet places himself in the centre of a 360-degree reality, on a ferryboat at sundown, moving between two cities, his shadow on the moving water, seeing from the moving ferry on that moving water the setting sun making a circle within his circle of perception: a spoked wheel shape on the water like a microcosm of his larger circle of perception, that aureole or halo effect expressing a sense of the shadow self's divinity. And all of this takes place all at once.

The tide moves, the ferry moves, and the poet moves with them. Yet he is also motionless, leaning on the boat's rail. He is the unmoving centre of the perspective, passively perceiving all. Paradoxically unmoving, he moves in the "float" of water, boat, all space and time. From passive observation he goes on in imagination to become the unifying force which keeps all things in existence. The poem's duration develops to a sense of this final control, as if all things would sink into separateness and meaninglessness if it were not for the poet's cohering force.

The catalogues at the beginning and end of the poem take place in specific time: the moments during and just after sundown. The darkness, lit up by foundry chimneys, at the end tells us that time has moved on during the poem's process.

But the tone of the last inventory is different from that of the inventory in Section 1. In Section 9, the poet names the same objects in the imperative voice, as if he keeps them in existence rather than merely naming them as he did in Section 1. It is as if the whole of reality might disappear if not for the poet's shaping power. Also, he himself might slip into nothingness if it were not for the "dumb, beautiful ministers" answering in a supportive way to his soul.

This imperative tone suggests an apprehension of reality - possessed realityquite at odds with the "museum reassurance" I spoke of earlier. In "Crossing Brooklyn Ferry" the poet perceives in a landscape without the comfort of surrounding walls. He moves in a "float" of being.

This word "float" is usually thought of as an expression of the infinite seas of the transcendental oversoul. Whitman took the word and image from chemistry. Solid particles when centrifuged in a liquid are not absorbed, but are diffused and held in the liquid for a time. Finally they come out of suspension and settle at the bottom.

In the poet's imagination singular objects in spatial reality are held "forever in suspension." For Whitman, the predominant sense through which these objects are known is that of sight. Secondarily, yet almost as important, is a kinestetic sense: an awareness of position in space, awareness of motion or stillness. It is this sense which informs the self of its own existence while sight informs the self of the existence of all outward reality.

This information creates a tension between two opposite apprehensions. One is a 
sympathy for others-both objects and other human beings. This sympathy increases to the point of merging with them in the present moment and in all future time. The other realization is a prideful superawareness of singular self. Hence, there is a strong, intense awareness of uniqueness and separateness coexisting with the merging.

They are reconciled in the poem. The panorama may be routine and mundane, but the reality that exists within that perceived circle never is.

Whitman's ferryboat moved in its mundane everyday course across the East River past beautiful seagulls, ships, the "scallop-edged waves" as well as past grimy industrial docks and foundry chimneys lighting up the night sky. During the flood tide, half an hour before sunset, the poet yearned for the flow of time and space to cease, but realized at the same time that life by definition is motion.

The sudden intuition of an inner nature which contained not only the transcendental oversoul but also the wolf, the snake and the hog, and his fellow passengers knowing that inner self (calling him by his "nighest" or nearest name) took place in that mundane and exalted moment, in a museum without walls. "Crossing Brooklyn Ferry" is the catalogue of that museum as well as a statement of Whitman's faith in the power of the imagination. And, unlike the three miles of canvas wound on Banvard's cylinders, Whitman's panorama needs no space. It revolves forever around the sacred spool of the poet's eternal imagination.

University of Windsor

EUgene MCNAMARA

\section{NOTES}

1 Prose Works 1892, ed. Floyd Stovall (New York: New York University Press, 1963), 1:16.

2 For a detailed study of the effect panoramas may have had on Whitman's poetry see Charles Zarobila's "Walt Whitman and the Panorama," Walt Whitman Review, 25 (1979), 51-58. Other American writers who refer to panoramas include Longfellow, Thoreau, Whittier, Melville and Mark Twain. Curtis Dahl's "Mark Twain and the Moving Panoramas," American Quarterly, 13 (Spring, 1961), 20-32, is a study of the possible influence of Banvard's panorama on Twain. See also Dorothy Anne Dondore, "Banvard's Panorama and the Flowering of New England," New England Quarterly, 11 (December 1938), 817-826.

3 Leaves of Grass, Comprehensive Reader' s Edition, ed. Harold W. Blodgett and Sculley Bradley (New York: New York University Press, 1965), p. 678.

\section{TWO LAMARCKIANS: WALT WHITMAN AND EDWARD CARPENTER}

Lamarckian theory is one link between Walt Whitman and the English prosewriter and poet, Edward Carpenter (1844-1929). Jean Lamarck (1744-1829), French evolutionist, theorized after long years of academic investigation the following two biological laws: (1) the development of effectiveness of organs are proportional to the use of those organs; and (2) everything acquired or changed during an 